Article

\title{
Antioxidant and Anti-Osteoporotic Activities of Aromatic Compounds and Sterols from Hericium erinaceum
}

\author{
Wei Li ${ }^{1}$, Sang Hyun Lee ${ }^{2}$, Hae Dong Jang ${ }^{2, *}$, Jin Yeul Ma ${ }^{1, *}$ and Young Ho Kim ${ }^{3, *}$ \\ 1 Korean Medicine (KM) Application Center, Korea Institute of Oriental Medicine, Daegu 41062, Korea; \\ liwei1986@kiom.re.kr \\ 2 Department of Food and Nutrition, Hannam University, Daejeon 34430, Korea; shlee@hnu.ac.kr \\ 3 College of Pharmacy, Chungnam National University, Daejeon 34134, Korea \\ * Correspondence: haedong@hnu.ac.kr (H.D.J.); jyma@kiom.re.kr (J.Y.M.); yhk@cnu.ac.kr (Y.H.K.); \\ Tel.: +82-42-629-8795 (H.D.J.); +82-53-940-3811 (J.Y.M.); +82-42-821-5933 (Y.H.K.)
}

Academic Editor: Derek J. McPhee

Received: 14 November 2016; Accepted: 2 January 2017; Published: 11 January 2017

\begin{abstract}
Hericium erinaceum, commonly called lion's mane mushroom, is a traditional edible mushroom widely used in culinary applications and herbal medicines in East Asian countries. In this study, a new sterol, cerevisterol 6-cinnamate (6), was isolated from the fruiting bodies of H. erinaceum together with five aromatic compounds 1-5 and five sterols 7-11. The chemical structures of these compounds were elucidated using chemical and physical methods and comparison of HRESIMS, ${ }^{1} \mathrm{D}-\mathrm{NMR}\left({ }^{1} \mathrm{H},{ }^{13} \mathrm{C}\right.$, and DEPT) and 2D-NMR (COSY, HMQC, HMBC, and NOESY) spectra with previously reported data. The antioxidant and anti-osteoporotic activities of extracts and the isolated compounds 1-11 were investigated. All compounds exhibited peroxyl radical-scavenging capacity but only compounds 1, 3, and 4 showed potent reducing capacity. Moreover, compounds 1, 2, 4, and 5 showed moderate effects on cellular antioxidant activity and inhibited the receptor activator of nuclear factor $\mathrm{KB}$ ligand (RANKL)-induced osteoclastic differentiation. These results suggested that $H$. erinaceum could be utilized in the development of natural antioxidant and anti-osteoporotic nutraceuticals and functional foods.
\end{abstract}

Keywords: Hericium erinaceum; hericiaceae; antioxidant; anti-osteoporosis; sterol; aromatic compound

\section{Introduction}

Oxidative stress is caused by an imbalance in the generation of reactive oxygen species (ROS) and the activity of antioxidant defenses. Severe oxidative stress has been implicated in many chronic and degenerative diseases, including osteoporosis, cancer, aging, and neurodegenerative diseases such as Alzheimer's disease, Parkinson's disease, and amyotrophic lateral sclerosis [1]. Several natural antioxidants have been reported, including flavonoids, coumarins, anthocyanins, and phenolic acids. Some natural flavonoids and coumarins with antioxidant activity, including scopoletin and baicalein, have been found to exert potent anti-osteoporotic effects through the suppression of osteoclast formation and tartrate-resistant acid phosphatase (TRAP) [2-4]. Therefore, interest in novel natural antioxidants has increased. Osteoclasts are tissue-specific macrophage polykaryons formed by the differentiation of monocyte/macrophage precursor cells at or near the bone surface in response to osteoclastogenic factors, particularly the receptor activator of nuclear factor $\mathrm{kB}$ ligand (RANKL), which performs important functions in osteoclast differentiation, including mediation and activation $[5,6]$. This developmental process results in TRAP expression in the differentiating cells, followed by their fusion to produce multinucleated cells capable of resorbing a mineralized matrix [7]. 
In our continuing search for antioxidant and anti-osteoporotic components from natural sources, we found that the $\mathrm{MeOH}$ extract of Hericium erinaceum showed potent effects. H. erinaceum, commonly called lion's mane mushroom, is an edible medicinal fungus found in China, Korea, and Japan, and is used as a raw material in a wide range of East Asian foods. Its fruiting bodies are used to treat gastric ulcers, chronic gastritis, and other digestive tract-related diseases [8]. The constituents of $H$. erinaceum include polysaccharides, heteropolysaccharides, diterpenoids, and aromatic compounds [9]. Previous pharmacological studies on compounds isolated from H. erinaceum also showed their stimulatory effects on nerve growth factor synthesis and antitumor activity $[10,11]$. However, no studies have investigated the active components of $H$. erinaceum with antioxidant and anti-osteoporotic activities. In this study, bioassay-guided isolation of the $\mathrm{CHCl}_{3}$ fraction of the $\mathrm{MeOH}$ extract of $H$. erinaceum yielded 11 compounds $\mathbf{1 - 1 1}$, which were evaluated for antioxidant activity using oxygen radical absorbance capacity (ORAC), cupric ion reducing antioxidant capacity (CUPRAC), and cellular antioxidant capacity (CAC) assays. Moreover, the anti-osteoporotic activities of these compounds were evaluated by investigating their inhibitory effects on osteoclastic differentiation.

\section{Results and Discussion}

Using combined chromatographic separations, 11 compounds, including five aromatic compounds 1-5 and six sterols 6-11, one of which is new (cerevisterol 6-cinnamate, compound 6), were isolated from the $\mathrm{CHCl}_{3}$ fraction of the $\mathrm{MeOH}$ extract of H. erinaceum fruiting bodies (Figure 1). The known compounds were identified as hericenone J (1) [12], N-dephenylethyl isohericerin (2), 4-[3', $7^{\prime}$-dimethyl2',6'-octadienyl]-2-formyl-3-hydroxy-5-methyoxy-benzylalcohol (3) [13], isohericerin (4) [14], hericerin (5) [14], (22E,24R)-ergosta-7,22-diene-3 $\beta, 5 \alpha, 6 \beta, 9 \alpha$-tetraol (7) [15], cerevisterol (8) [16], blazein (9) [16], $3 \beta, 5 \alpha$-dihydroxy- $6 \beta$-acetoxy-ergosta-7,22-diene (10) [17], and ergosta-7,22-diene- $3 \beta, 5 \alpha, 6 \alpha$-triol (11) [18]. The purity of all isolated compounds was confirmed to be $>95 \%$ using HPLC. Compound structures were elucidated by comparison of spectroscopic data with reported values. Six compounds (6-11) were isolated from $H$. erinaceum for the first time.

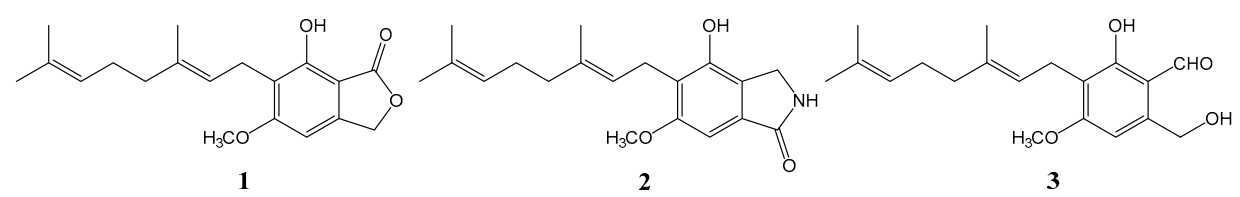<smiles>CC(C)=CCC/C(C)=C/CC1=C(O)C=C2CC(CCC3CCCCC3)C(=O)C2C1O</smiles><smiles>CC(C)=CCC/C(C)=C/CC1=C(O)C(O)C2CC(CCCc3ccccc3)C(=O)C2C1</smiles>

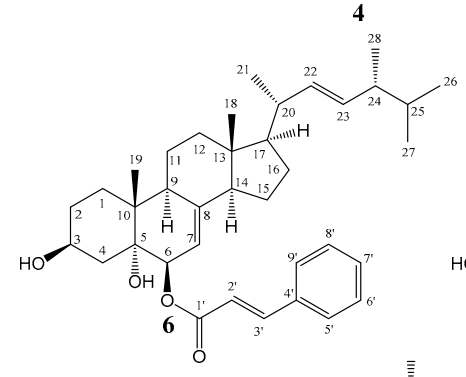

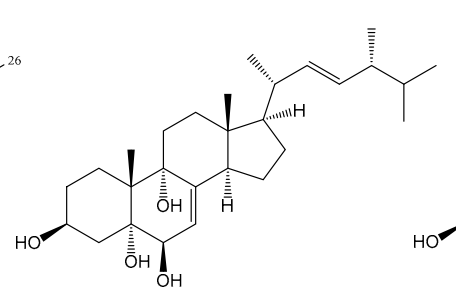

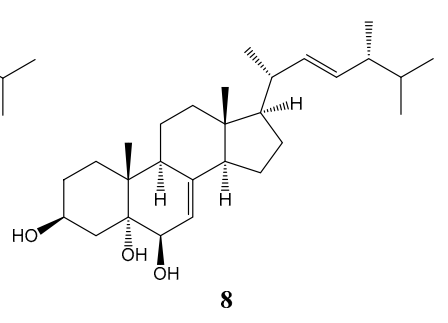

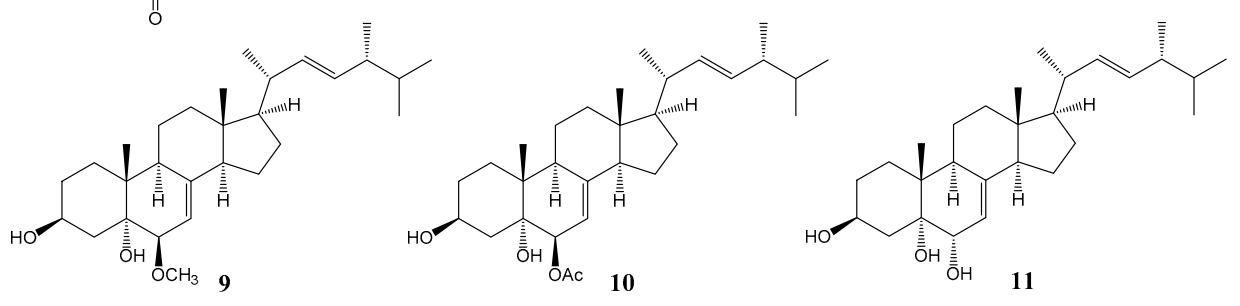

Figure 1. Structures of compounds 1-11 isolated from cultures of H. erinaceum. 
Compound 6 was obtained as a yellowish oil. The molecular formula $\mathrm{C}_{37} \mathrm{H}_{52} \mathrm{O}_{4}$ was assigned based on a pseudomolecular ion peak at $m / z 561.3944[\mathrm{M}+\mathrm{H}]^{+}$(calcd. 561.3938) in the HR-ESI-MS spectrum. The ${ }^{1} \mathrm{H}-\mathrm{NMR}$ spectrum of $\mathbf{6}$ (Table 1) contained peaks corresponding to six methyl groups [ $\delta_{\mathrm{H}} 0.53$ (s, Me-18), $0.76(\mathrm{~d}, J=6.5 \mathrm{~Hz}, \mathrm{Me}-26,27), 0.84(\mathrm{~d}, J=6.7 \mathrm{~Hz}, \mathrm{Me}-28), 0.95(\mathrm{~d}, J=6.5 \mathrm{~Hz}$, Me-21), and 1.08 (s, Me-19)], two oxymethines [ $\delta_{\mathrm{H}} 4.02(\mathrm{~m}, \mathrm{H}-3 \alpha)$ and $\left.4.93(\mathrm{~d}, J=5.4 \mathrm{~Hz}, \mathrm{H}-6 \alpha)\right]$, and three olefinic protons at $\delta_{\mathrm{H}} 5.09(\mathrm{dd}, J=15.3,7.7 \mathrm{~Hz}, \mathrm{H}-22), 5.14(\mathrm{dd}, J=15.3,7.0 \mathrm{~Hz}, \mathrm{H}-23)$, and $5.26(\mathrm{~d}, J=5.4 \mathrm{~Hz}, \mathrm{H}-7)$. Additionally, cinnamic acid residue signals were observed at $\delta_{\mathrm{H}} 6.33(\mathrm{~d}$, $\left.J=16.0 \mathrm{~Hz}, \mathrm{H}-2^{\prime}\right), 7.30-7.31\left(\mathrm{~m}, \mathrm{H}-6^{\prime}, 7^{\prime}, 8^{\prime}\right), 7.46\left(\mathrm{~d}, J=8.0 \mathrm{~Hz}, \mathrm{H}-5^{\prime}, 9^{\prime}\right)$, and $7.58\left(\mathrm{~d}, J=16.0 \mathrm{~Hz}, \mathrm{H}-3^{\prime}\right)$. The ${ }^{13} \mathrm{C}$-NMR spectrum (Table 1) contained 28 resonances corresponding to the sterol moiety, which were assigned to six methyl groups $\left(\delta_{C} 12.5,17.6,18.5,19.7,20.3\right.$, and 21.2$)$, seven methylene groups $\left(\delta_{C} 22.2,22.8,27.9,30.7,32.6,39.3\right.$, and 39.4), eight sp ${ }^{3}$ methine groups $\left(\delta_{C} 33.1,40.4,43.4,55.0,56.0\right.$, 67.5 , and 73.5), three $\mathrm{sp}^{2}$ methine groups $\left(\delta_{C} 114.3,132.2\right.$, and 135.4), and four quaternary carbon atoms $\left(\delta_{C} 37.3,43.9,75.5\right.$, and 145.9). Signals from the cinnamic acid residue revealed a carbonyl group [ $\left.\delta_{\mathrm{C}} 166.4\left(\mathrm{C}-1^{\prime}\right)\right]$, two olefinic carbon atoms $\left[\delta_{\mathrm{C}} 118.4\left(\mathrm{C}-2^{\prime}\right)\right.$ and $145.1\left(\mathrm{C}-3^{\prime}\right)$ ] and six aromatic carbon atoms $\left[\delta_{C} 128.2\left(C-5^{\prime}, 9^{\prime}\right), 128.9\left(C-6^{\prime}, 8^{\prime}\right), 130.4\left(C-7^{\prime}\right)\right.$, and $\left.134.4\left(C-4^{\prime}\right)\right]$. The above data showed that the sterol moiety 6 was a $\Delta^{7}$-ergostane derivative, which was similar to compound 8 (cerevisterol) [19], but had a cinnamic acid residue attached at C-6. This finding was supported by a key HMBC correlation between $\mathrm{H}-6 \alpha\left(\delta_{\mathrm{H}} 4.93\right)$ and $\mathrm{C}-1^{\prime}\left(\delta_{\mathrm{C}}\right.$ 166.4) (Figure 2$)$. Alkaline hydrolysis of 6 with $0.5 \% \mathrm{NaOH}$ yielded cerevisterol and cinnamic acid, which were identified by TLC analysis $\left(\mathrm{CHCl}_{3}\right.$-acetone: $2: 1$; $R_{\mathrm{f}}=0.35,0.80$ ) with known standards (see Supplementary Materials).

Table 1. ${ }^{1} \mathrm{H}(600 \mathrm{MHz})$ and ${ }^{13} \mathrm{C}-\mathrm{NMR}(150 \mathrm{MHz})$ spectroscopic data of compound $6\left(\mathrm{CDCl}_{3}, \delta(\mathrm{ppm})\right.$, $J(\mathrm{~Hz}))$.

\begin{tabular}{|c|c|c|c|c|c|}
\hline Pos. & $\delta_{H}$ & $\delta_{C}$ & Pos. & $\delta_{H}$ & $\delta_{C}$ \\
\hline 1 & $\begin{array}{l}1.57, \mathrm{~m} \\
1.97, \mathrm{~m}\end{array}$ & 32.6 & 20 & $1.99, \mathrm{~m}$ & 40.4 \\
\hline 2 & $1.41, \mathrm{~m}$ & 30.7 & 21 & $0.95, d, 6.5$ & 21.2 \\
\hline 3 & $4.02, \mathrm{~m}$ & 67.5 & 22 & $5.09, \mathrm{dd}, 15.3,7.7$ & 135.4 \\
\hline 4 & $\begin{array}{l}1.69, \mathrm{~m} \\
1.87, \mathrm{~m}\end{array}$ & 39.4 & 23 & $5.14, \mathrm{dd}, 15.3,7.0$ & 132.2 \\
\hline 5 & - & 75.5 & 24 & $1.80, \mathrm{~m}$ & 42.9 \\
\hline 6 & $4.93, d, 5.4$ & 73.5 & 25 & $1.40, \mathrm{~m}$ & 33.1 \\
\hline 7 & $5.26, d, 5.4$ & 114.3 & 26 & $0.76, d, 6.5$ & 20.3 \\
\hline 8 & - & 145.9 & 27 & $0.76, d, 6.5$ & 19.7 \\
\hline 9 & $1.94, \mathrm{~m}$ & 43.4 & 28 & $0.84, d, 6.7$ & 17.6 \\
\hline 10 & - & 37.3 & $\mathbf{1}^{\prime}$ & - & 166.4 \\
\hline 11 & $1.55, \mathrm{~m}$ & 22.2 & $2^{\prime}$ & $6.33, d, 16.0$ & 118.4 \\
\hline 12 & $\begin{array}{l}1.27, \mathrm{~m} \\
1.68, \mathrm{~m}\end{array}$ & 39.3 & $3^{\prime}$ & $7.58, \mathrm{~d}, 16.0$ & 145.1 \\
\hline 13 & - & 43.9 & $4^{\prime}$ & - & 134.4 \\
\hline 14 & $1.87, \mathrm{~m}$ & 55.0 & $5^{\prime}$ & $7.46, d, 8.0$ & 128.2 \\
\hline 15 & $\begin{array}{l}1.35, \mathrm{~m} \\
1.51, \mathrm{~m}\end{array}$ & 22.8 & $6^{\prime}$ & 7.30-7.31, m & 128.9 \\
\hline 16 & $\begin{array}{l}1.21, \mathrm{~m} \\
1.67, \mathrm{~m}\end{array}$ & 27.9 & $7^{\prime}$ & 7.30-7.31, m & 130.4 \\
\hline 17 & $1.22, \mathrm{~m}$ & 56.0 & $8^{\prime}$ & $7.30-7.31, \mathrm{~m}$ & 128.9 \\
\hline 18 & $0.53, \mathrm{~s}$ & 12.5 & $9^{\prime}$ & $7.46, d, 8.0$ & 128.2 \\
\hline 19 & $1.08, \mathrm{~s}$ & 18.5 & & & \\
\hline
\end{tabular}



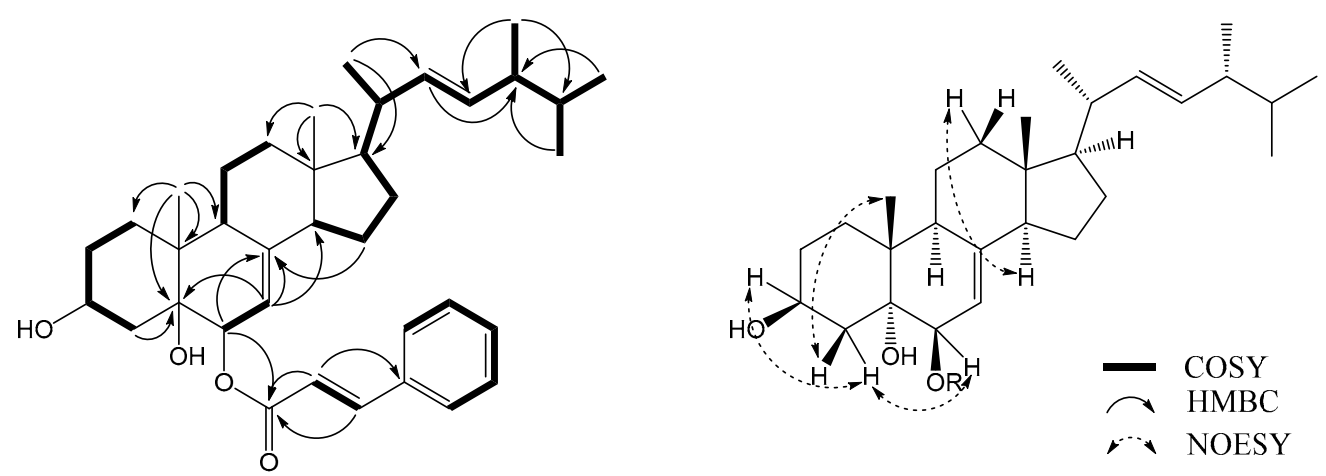

Figure 2. Key ${ }^{1} \mathrm{H}^{-1} \mathrm{H}$ COSY, HMBC, and NOESY correlations of compound 6.

The relative configuration of $\mathbf{6}$ was determined using a NOESY NMR experiment and empirical pyridine-induced deshielding effects. NOE correlations were observed between $\mathrm{H}-6 \alpha\left(\delta_{\mathrm{H}} 4.93\right)$ and $\mathrm{H}_{\mathrm{eq}}-4\left(\delta_{\mathrm{H}} 1.69\right), \mathrm{H}-3 \alpha\left(\delta_{\mathrm{H}} 4.02\right)$ and $\mathrm{H}_{\mathrm{eq}}-4\left(\delta_{\mathrm{H}} 1.69\right)$, and Me-19 $\left(\delta_{\mathrm{H}} 1.08\right)$ and $\mathrm{H}_{\mathrm{ax}}-4\left(\delta_{\mathrm{H}} 1.87\right)$, which indicated that the two hydroxyl groups were in $3 \beta, 6 \beta$-orientations (Figure 2) $[18,19]$. The chemical shifts of $\mathrm{H}_{\mathrm{ax}}-3, \mathrm{H}_{\mathrm{ax}}-4, \mathrm{H}-6$, and Me-19 measured in pyridine- $d_{5}$ were shifted downfield, which indicated the presence of a $3 \beta, 5 \alpha, 6 \beta$-trihydroxylated system in compound $6[15,20]$. A comparison of the chemical shifts of C-26, C-27, and C-28 of 6 with those of compound 8 established a $24 R$ configuration in 6 [21]. The large coupling constant $(15.3 \mathrm{~Hz})$ between $\mathrm{H}-22$ and H-23 was indicative of an $E$ configuration for the double bond [22]. Therefore, compound 6 was identified as cerevisterol 6-cinnamate [(22E,24R)-ergosta-7,22-dien-3 $\beta, 5 \alpha, 6 \beta$-triol 6-cinnamate].

The $\mathrm{MeOH}$ extract and $\mathrm{CHCl}_{3}$ and water fractions of $\mathrm{H}$. erinaceum were evaluated for their antioxidant activity at concentrations of 1.0 and $10.0 \mu \mathrm{g} / \mathrm{mL}$. The $\mathrm{MeOH}$ extract and $\mathrm{CHCl}_{3}$ fraction showed potent effects at $10.0 \mu \mathrm{g} / \mathrm{mL}$ in the ORAC and CUPRAC assays (Figure 3A,C). In order to identify the active antioxidant and anti-osteoporotic components of $H$. erinaceum, 11 compounds (1-11) from the $\mathrm{CHCl}_{3}$ fraction were evaluated using ORAC, CUPRAC, CAC, and TRAP assays. The antioxidant activities of compounds 1-11 were investigated by ORAC and CUPRAC assays. The ORAC assay is based on hydrogen atom transfer while the CUPRAC reducing capacity assay depends on single electron transfer [23]. The results showed that compounds 1, 3, and $\mathbf{6}$ had potent peroxyl radical-scavenging activities at $10 \mu \mathrm{M}$ with ORAC values of $6.05,4.98$, and 8.01 , respectively. Other compounds showed negligible activities with ORAC values below 4.00 (Figure 3B). In structure-activity analysis of the isolated compounds, the aromatic compounds $\mathbf{1}$ and $\mathbf{3}$ showed more potent activity than the other aromatic compounds $(2,4$, and 5$)$. The same hydroxyl group is present in the aromatic ring but compounds $\mathbf{2 , 4}$, and 5 also contain a nitrogen atom. Therefore, it appears that the nitrogen atom in the aromatic ring exerts a negative influence on peroxyl radical-scavenging activity. Compound $\mathbf{6}$ exhibited the strongest activity among the isolated sterols (6-11). Based on structural analysis, the cinnamic acid residue at C-6 seems to be an important element for peroxyl radical-scavenging activity.

The ability to transfer single electrons was examined by reducing capacity assay. The reducing capacity of all compounds was evaluated based on the production of $\mathrm{Cu}(\mathrm{I})$ ions from $\mathrm{Cu}$ (II) ions in the presence of each isolated compound. The results revealed that only compounds $\mathbf{1}$ and $\mathbf{3}$ exhibited an obvious reducing capacity at $10.0 \mu \mathrm{M}$, with CUPRAC values of 6.16 and 5.16, respectively (Figure 3D). These results indicated that the ability of compounds $\mathbf{1}$ and $\mathbf{3}$ to donate hydrogen atoms or electrons to peroxyl radicals, and to convert them into relatively stable compounds, may contribute to their peroxyl radical-scavenging capacity.

The intracellular antioxidant capacities of compounds 1-11 were investigated by a CAC assay. First, cell viability was tested by an MTT assay. The results showed that compounds 1-11 were not significantly cytotoxic to HepG2 cells at the tested concentrations. Following treatment with AAPH, intracellular oxidative stress in HepG2 cells increased to $213.8 \%$ of the control value. As shown 
in Figure 4, all 11 compounds decreased the intracellular oxidative stress caused by AAPH to $111.6 \%-177.7 \%$ of the control value. Thus, all the isolated compounds may permeate the cell membrane and suppress the intracellular oxidative stress induced by peroxyl radicals.
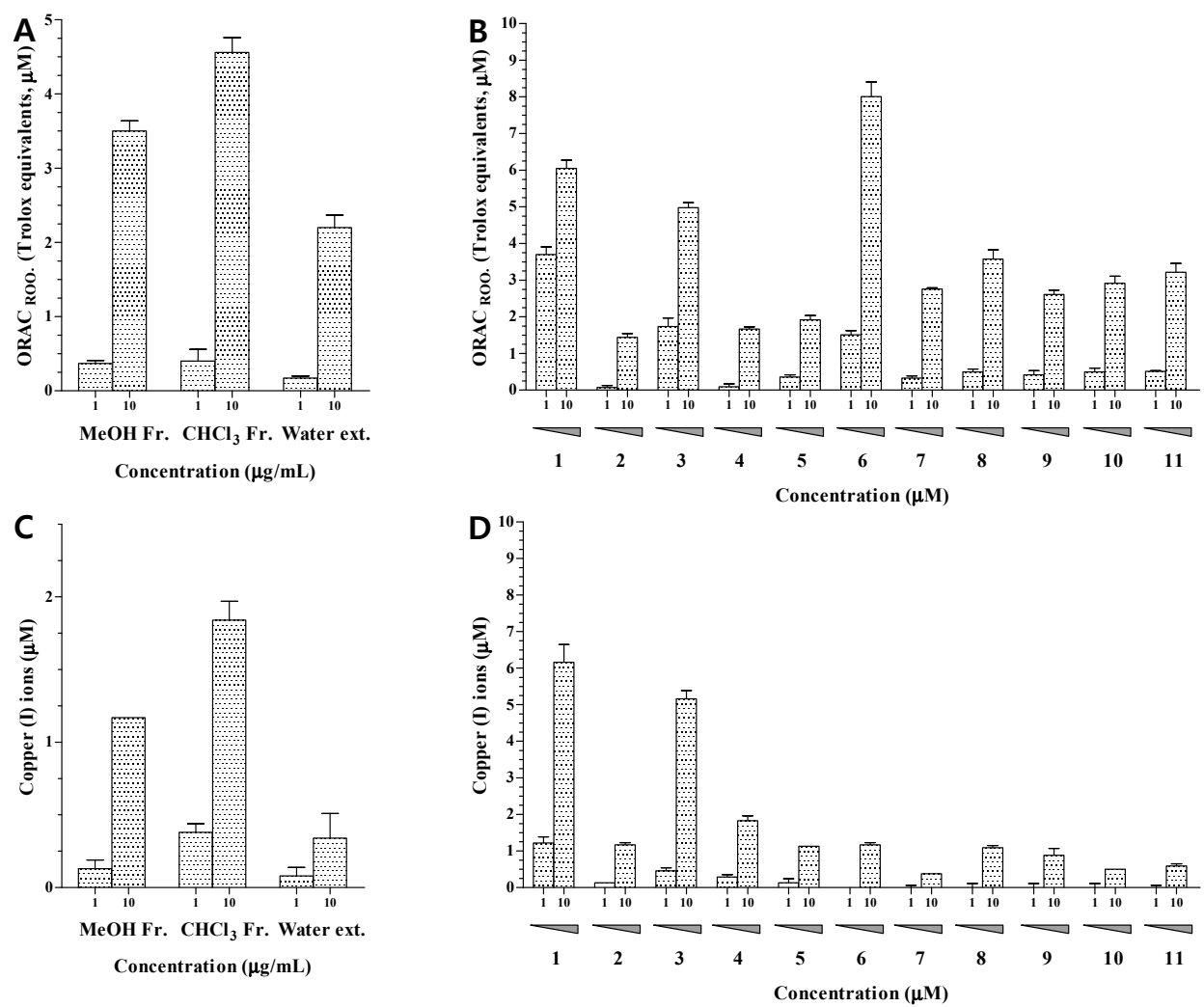

Figure 3. Peroxyl radical-scavenging capacity $((\mathbf{A}, \mathbf{B}))$ and reducing capacity $((\mathbf{C}, \mathbf{D}))$ of the extracts and compounds 1-11 from $H$. erinaceum. Data are expressed as the mean \pm standard deviation of three individual experiments. Statistical significance is determined by one-way ANOVA followed by Dunnett's multiple comparison test $(p<0.05)$.

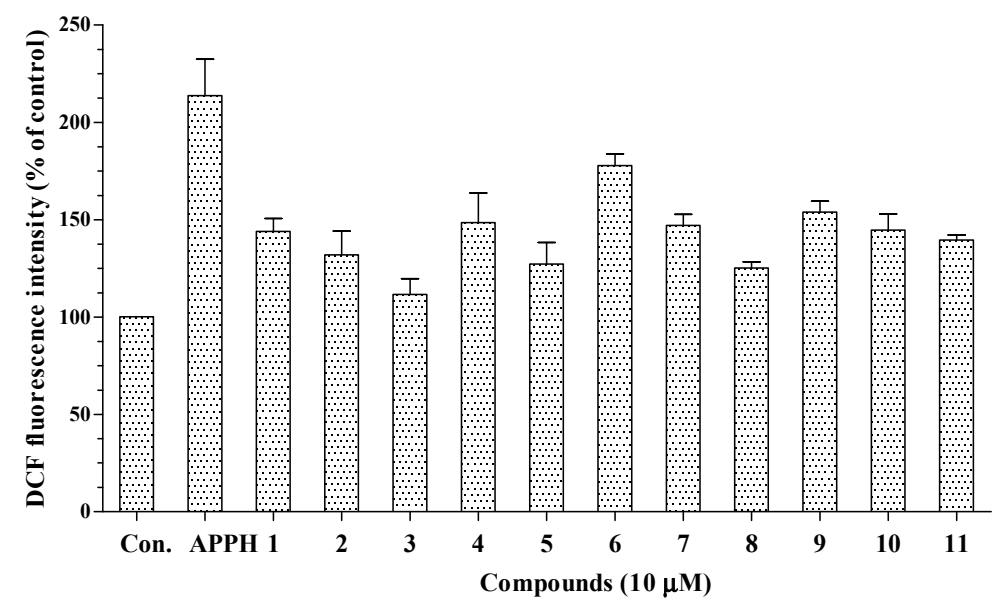

Figure 4. Cellular antioxidant capacity of compounds 1-11 against oxidative stress induced by 2,2'-azobisisobutyramidinium chloride (APPH) (Con.: control). Data are expressed as percentages of the value of untreated cells (mean \pm standard deviation of three individual experiments). Statistical significance is determined by one-way ANOVA followed by Dunnett's multiple comparison test $(p<0.05)$. 
The $\mathrm{MeOH}$ extract and $\mathrm{CHCl}_{3}$ fraction also exhibited moderate TRAP activity at $10.0 \mu \mathrm{g} / \mathrm{mL}$ (Figure 5A). We also investigated the anti-osteoporotic activity of compounds 1-11 by evaluating their inhibitory effects on TRAP activity in osteoclasts differentiated from RAW 264.7 cells. Osteoclast differentiation was induced by RANKL, a key cytokine regulating osteoclastogenesis and bone resorption. RANKL treatment strongly induced osteoclast formation from RAW 264.7 pre-osteoclasts and markedly increased TRAP activity [24]. TRAP is highly expressed in osteoclasts and is widely used as a phenotypic marker of osteoclasts. Based on the reduction in TRAP activity, the inhibitory activities of compounds 1-11 against osteoporosis are shown in Figure 5. At a concentration of $10 \mu \mathrm{M}$, compounds 8-11 showed strong inhibition of RANKL-induced TRAP activity, reducing it to $28.1 \%, 74.8 \%, 81.8 \%$, and $138.9 \%$, respectively, from a value of $332 \%$ in RANKL-treated control cells. The potent inhibitory effects of compounds 8-11 may be due to their strong cytotoxicity. In contrast, compounds 1, 2, 4, and 5 showed moderate inhibition at $10 \mu \mathrm{M}$ (Figure 5B), which indicated that the presence of an $\alpha, \beta$-unsaturated carbonyl moiety in the structure may be involved in the inhibitory effects on the TRAP activity of osteoclasts.
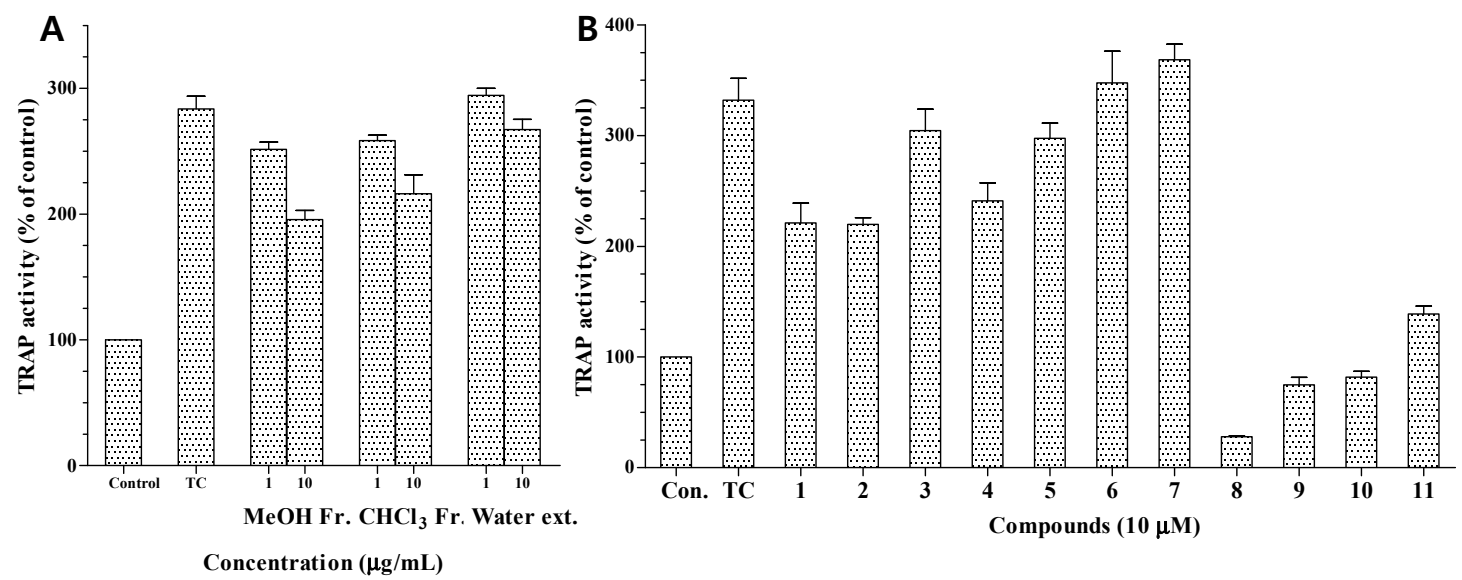

Figure 5. Inhibitory effects of the extracts (A) and compounds 1-11 (B) on TRAP activity of osteoclastic RAW 264.7 cells. Data are expressed as percentages of the values obtained with untreated cells. (Con.: control, which was not treated; TC: treated control, which was treated with RANKL).

Recent studies have suggested that intracellular antioxidant activity related to ROS scavenging may be responsible for increased osteoblast differentiation in MC3T3-E1 pre-osteoblastic cells and suppression of the differentiation of RAW 264.7 pre-osteoclast cells into osteoclasts [2,25]. However, a comparison of the anti-osteoporotic and antioxidant activities of compounds 1-11 indicated their anti-osteoporotic activity appeared to be associated with cellular antioxidant activity instead of in vitro antioxidant activity, but was not proportional to cellular antioxidant activity. These results can be explained by the different plausible mechanisms that may contribute to cellular antioxidant activities, such as the induction of phase II detoxifying and antioxidant enzymes as an indirect source of antioxidant activity. In addition, the important role of the $\alpha, \beta$-unsaturated carbonyl moiety in the indirect cellular antioxidant activity of these compounds (1, 2, 4, and 5) can be ignored. However, more research is required to determine whether the potent anti-osteoporotic activities of compounds $\mathbf{1}$, 2,4 , and 5 result from indirect antioxidant activity.

\section{Materials and Methods}

\subsection{General Information}

Optical rotations were determined using a DIP-370 automatic polarimeter (Jasco, Easton, MD, USA). The FT-IR spectra were measured using a Jasco Report-100 infrared spectrometer; The NMR spectra were recorded using an ECA 600 spectrometer $\left({ }^{1} \mathrm{H}, 600 \mathrm{MHz} ;{ }^{13} \mathrm{C}, 150 \mathrm{MHz}\right.$, JEOL, Tokyo, 
Japan). Mass spectra were recorded on an LCQ advantage trap mass spectrometer (Thermo Finnigan, San Jose, CA, USA) equipped with an electrospray ionization (ESI) source. High-resolution electrospray ionization mass spectra (HR-ESI-MS) were obtained using a 6530 Accurate-Mass Q-TOF LC/MS system (Agilent, Santa Clara, CA, USA). Column chromatography was performed using silica gel (Kieselgel 60, 70-230, and 230-400 mesh, Merck, Darmstadt, Germany) and YMC RP-18 resins (Merck), and thin layer chromatography (TLC) was performed using pre-coated silica-gel $60 \mathrm{~F}_{254}$ and $\mathrm{RP}-18 \mathrm{~F}_{254} \mathrm{~S}$ plates (both $0.25 \mathrm{~mm}$, Merck).

\subsection{Fungal Material}

Dried fruiting bodies of $H$. erinaceum were purchased from an herbal market in Kumsan, Chungnam Province, Korea in August 2013. The identity of the specimens was confirmed by one of authors (Young Ho Kim). A voucher specimen (CNU 13110) was deposited at the Herbarium of the College of Pharmacy at Chungnam National University.

\subsection{Fermentation, Extraction and Isolation}

Dried fruiting bodies $(2.5 \mathrm{~kg})$ of $\mathrm{H}$. erinaceum were extracted with $\mathrm{MeOH}(5 \mathrm{~L}, \times 3)$ under reflux. The $\mathrm{MeOH}$ extract $(320.0 \mathrm{~g})$ was suspended in water $(5.0 \mathrm{~L})$ and partitioned with $\mathrm{CHCl}_{3}(5.0 \mathrm{~L})$ yielding $\mathrm{CHCl}_{3}(90.0 \mathrm{~g})$ and water $(220.0 \mathrm{~g})$ fractions. The $\mathrm{CHCl}_{3}$ fraction $(90.0 \mathrm{~g})$ was subjected to silica gel $(5.0 \mathrm{~cm} \times 30 \mathrm{~cm})$ column chromatography with a gradient of $n$-hexane-EtOAc-MeOH (25:1:0, 9:1:0, 5:1:0, 2.5:1:0, 1:1:0.1, 1:1:0.3, 0.5:1:0.5; $4 \mathrm{~L}$ for each step) to give eight fractions (Fr. 1A-1H).

Fraction 1C was separated on a silica gel column with a gradient of $n$-hexane-EtOAc (20:1 to $10: 1,10 \mathrm{~L}$ ) to give 11 sub-fractions (Fr. 1C-1-1C-11). Fraction 1C-8 was subjected to YMC $(1.0 \times 80 \mathrm{~cm})$ column chromatography eluted with a $\mathrm{MeOH}$-acetone- $\mathrm{H}_{2} \mathrm{O}(3: 3: 1,4: 4: 1,6: 6: 1 ; 1.2 \mathrm{~L}$ for each step) gradient to give compounds $1(43.6 \mathrm{mg})$ and $5(86.2 \mathrm{mg})$. Fraction 1D was subjected to silica gel $(2.5 \mathrm{~cm} \times 30 \mathrm{~cm})$ column chromatography with a gradient of $n$-hexane-EtOAc-MeOH (8:1:0.15, 6:1:0.15, 4:1:0.15, 3:1:0.15, 2:1:0.15, 1.5:1:0.15; $2.5 \mathrm{~L}$ for each step) to give 10 fractions (Fr. 1D-1-1D-10). Fraction 1D-7 was subjected to YMC $(1.5 \mathrm{~cm} \times 80 \mathrm{~cm})$ column chromatography eluting with a $\mathrm{MeOH}$-acetone- $\mathrm{H}_{2} \mathrm{O}$ (1.5:1:1, 3:1.5:1, 6:3.5:1, 9:5:1; $1.0 \mathrm{~L}$ for each step) gradient to give compound $3(21.4 \mathrm{mg})$. Fraction 1D-8 was subjected to silica gel $(1.0 \mathrm{~cm} \times 80 \mathrm{~cm})$ column chromatography with a $n$-hexane-EtOAc-acetone $(3: 1: 0.15 ; 750 \mathrm{~mL})$ mixture as eluent to give compound $4(13.4 \mathrm{mg})$. Fraction 1D-9 was subjected to YMC $(2.5 \mathrm{~cm} \times 80 \mathrm{~cm})$ column chromatography eluting with $\mathrm{MeOH}$-acetone- $\mathrm{H}_{2} \mathrm{O}$ (1:1:1, 2:2:1, 3:3:1, 5:5:1, 8:8:1, 10:10:1; $3 \mathrm{~L}$ for each step) to give eight sub-fractions (Fr. 1D-9-A-1D-9-H). Fraction 1D-9-E was subjected to silica gel $(1.5 \mathrm{~cm} \times 80 \mathrm{~cm})$ column chromatography with a $\mathrm{CHCl}_{3}$-acetone (7:1, 9:1, 12:1; $1 \mathrm{~L}$ for each step) eluent to give compounds 9 (12.0 mg), $10(7.0 \mathrm{mg})$, and $11(22.0 \mathrm{mg})$. 1D-10 was subjected to YMC $(2.5 \mathrm{~cm} \times 80 \mathrm{~cm})$ column chromatography eluting with $\mathrm{MeOH}-\mathrm{H}_{2} \mathrm{O}(1: 1,2: 1,3: 1,5: 1,7: 1,9: 1,11: 1,13: 1,15: 1 ; 2.5 \mathrm{~L}$ for each step) to give seven sub-fractions (Fr. 1D-10-A-1D-10-G) and compound 7 (42.0 mg). Fraction 1D-10-F was subjected to silica gel $(1.0 \mathrm{~cm} \times 80 \mathrm{~cm})$ column chromatography with $\mathrm{CHCl}_{3}$-acetone $(2.3: 1 ; 1 \mathrm{~L})$ as elution solvent to give compounds $6(7.4 \mathrm{mg})$ and $8(19.0 \mathrm{mg})$. Fraction 1E was separated using YMC $(1.0 \mathrm{~cm} \times 80 \mathrm{~cm})$ column chromatography with $\mathrm{MeOH}-\mathrm{H}_{2} \mathrm{O}$ mixtures $(1: 1,3: 1,5: 1,7.5: 1,9: 1,15: 1$; $300 \mathrm{~mL}$ for each step) as eluent to give compound $\mathbf{2}(11.8 \mathrm{mg})$.

\subsection{Product Characterization}

Cerevisterol 6-cinnamate (6): Yellowish oil; $\mathrm{C}_{12} \mathrm{H}_{12} \mathrm{O}_{5} ;[\alpha]_{D}^{25}$ : -21.8 (c $\left.0.2, \mathrm{MeOH}\right) ;{ }^{1} \mathrm{H}-\mathrm{NMR}\left(\mathrm{CDCl}_{3}\right.$, $600 \mathrm{MHz})$ and ${ }^{13} \mathrm{C}-\mathrm{NMR}$ data $\left(\mathrm{CDCl}_{3}, 150 \mathrm{MHz}\right)$, see Table 1 ; HR-ESI-MS $\left(\mathrm{C}_{37} \mathrm{H}_{52} \mathrm{O}_{4}\right): m / z 561.3944$ $[\mathrm{M}+\mathrm{H}]^{+}$(calcd. 561.3938).

\subsection{Cell Toxicity Assay}

Cell-Counting Kit (CCK)-8 (Dojindo, Kumamoto, Japan) was used to analyze the effect of compounds on cell toxicity according to the manufacturer's instructions. Cells were cultured overnight 
in a 96-well plate $\left(\sim 1 \times 10^{4}\right.$ cells /well). Cell toxicity was assessed after the addition of compounds on dose-dependent manner. After $24 \mathrm{~h}$ of treatment, $10 \mu \mathrm{L}$ of the CCK-8 solution was added to triplicate wells, and incubated for $1 \mathrm{~h}$. Absorbance was measured at $450 \mathrm{~nm}$ to determine viable cell numbers in wells.

\subsection{Oxygen Radical Absorbance Capacity (ORAC) Assay}

The assay was performed on a Tecan GENios multi-functional plate reader (Tecan, Salzburg, Austria) with fluorescent filters using excitation and emission wavelengths of 485 and $535 \mathrm{~nm}$, respectively. In the final assay mixture, $40 \mathrm{nM}$ fluorescein was used as a target of free radical attack with $20 \mathrm{mM}$ 2,2-azobis dihydrochloride (AAPH) as a peroxyl radical generator [26]. Trolox (1.0 $\mu \mathrm{M})$ was used as a control standard and prepared fresh daily. The analyzer was programmed to record the fluorescence of fluorescein every $2 \mathrm{~min}$ after the addition of AAPH. Fluorescein $(40 \mathrm{nM})$ in potassium phosphate buffer was used as the blank. All fluorescence measurements were expressed relative to the initial reading. Final results were calculated based on the difference in area under the fluorescence

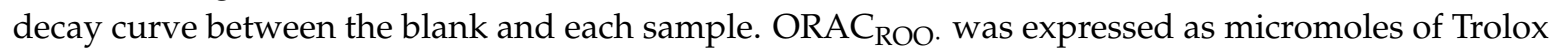
equivalents (TE). One ORAC unit is equivalent to the net protection area of $1.0 \mu \mathrm{M}$ of Trolox.

\subsection{Reduction Capacity}

The reducing abilities of isolated compounds were determined according to the CUPRAC assay [27]. A total of $40 \mu \mathrm{L}$ of different concentrations of the compounds in distilled water were mixed with $160 \mu \mathrm{L}$ of a mixture containing $0.5 \mathrm{mM} \mathrm{CuCl}_{2}$ and $0.75 \mathrm{mM}$ neocuproine in $10 \mathrm{mM}$ phosphate buffer, $\mathrm{pH}$ 7.4. The absorbance was measured using a micro-plate reader at $454 \mathrm{~nm}$ for $1 \mathrm{~h}$. The increase in the absorbance of the reaction mixture was indicative of increased reducing power. Distilled water was used as the blank.

\subsection{Cellular Antioxidant Capacity}

Cellular oxidative stress due to ROS generated by AAPH was measured spectrofluorometrically using the DCFH-DA method [28]. DCFH-DA diffuses through the cell membrane and is enzymatically hydrolyzed by intracellular esterase to non-fluorescent DCFH, which is rapidly oxidized to highly fluorescent DCF in the presence of ROS. HepG2 cells were first cultured in 96-well plates $\left(5 \times 10^{5} / \mathrm{mL}\right)$ with DMEM for $24 \mathrm{~h}$. After the cells were incubated with different concentrations of extracts and isolated compounds dissolved in DMSO for $30 \mathrm{~min}$, the medium was discarded, and the wells were gently washed twice with PBS. HBSS, which is fluorescently stable, was then added to each well instead of normal medium, and AAPH was used as an oxidative stress inducer. After the cells were treated with $60 \mu \mathrm{M}$ AAPH for $30 \mathrm{~min}$, DCFHDA was added to the culture plates at a final concentration of $40 \mu \mathrm{M}$ and incubated for $30 \mathrm{~min}$ at $37^{\circ} \mathrm{C}$ in the dark. Trolox $(10 \mu \mathrm{M})$ was used as the positive control. After the incubation, the cells were washed with HBSS, and DCF fluorescence intensity was measured at an excitation wavelength of $485 \mathrm{~nm}$ and an emission wavelength of $535 \mathrm{~nm}$ using a Tecan GENios fluorometric plate reader. DMEM medium was used as the control.

\subsection{Tartrate-resistant Acid Phosphatase (TRAP) Activity}

RAW264.7 cells were seeded in 96-well plates $\left(1 \times 10^{4}\right.$ cells/well $)$ containing DMEM medium plus $10 \%$ fetal bovine serum (FBS) and the medium was replaced with test samples in a differentiation medium containing $50 \mathrm{ng} / \mathrm{mL}$ RANKL. After differentiating the RAW 264.7 cells into osteoclasts for 5 days, the medium was removed, and the cell monolayer was gently washed twice using ice-cold PBS. The cells were fixed in 3.5\% formaldehyde for $10 \mathrm{~min}$ and ethanol-acetone (1:1) for $1 \mathrm{~min}$. Subsequently, the dried cells were incubated in $50 \mathrm{mM}$ citrate buffer ( $\mathrm{pH} 4.5)$ containing $10 \mathrm{mM}$ sodium tartrate and $6 \mathrm{mM}$ p-nitrophenylphosphate (PNPP). After $1 \mathrm{~h}$ incubation, the reaction mixtures were transferred to new well plates containing an equal volume of $0.1 \mathrm{~N} \mathrm{NaOH}$. Absorbance was measured at $408 \mathrm{~nm}$ using an ELISA reader. Control was treated with only DMEM medium and treated control was treated 
with DMEM medium containing $50 \mathrm{ng} / \mathrm{mL}$ RANKL. TRAP activity was expressed as a percentage of the control.

\section{Conclusions}

In this study, a new sterol (cerevisterol 6-cinnamate; 6), together with 10 known compounds 1-5 and 7-11 were isolated from the fruiting bodies of $H$. erinaceum. All compounds exhibited peroxyl radical-scavenging capacity, while compounds 1, 3, and 4 showed reducing capacity too. Moreover, some sterols showed moderate effects on cellular antioxidant activity and inhibited RANKL-induced osteoclastic differentiation. To the best of our knowledge, this is the first report on the antioxidant and anti-osteoporotic activities of aromatic compounds and sterol components from H. erinaceum. These results provide a scientific basis for the development of novel antioxidant and anti-osteoporotic agents from this mushroom.

Supplementary Materials: The following are available online at: http://www.mdpi.com/1420-3049/22/1/108/s1, The NMR $\left({ }^{1} \mathrm{D}\right.$ and $\left.{ }^{2} \mathrm{D}\right)$ data of compound 6 are available as supporting information.

Acknowledgments: This research was supported by Chungnam National University and a grant (K17281) awarded to the Korean Institute of Oriental Medicine by the Ministry of Education, Science and Technology (MEST), Korea.

Author Contributions: W. Li performed the isolation, structure elucidation of the constituents, and prepared the manuscript. J.Y. Ma contributed to the revision of this manuscript. S.H. Lee and H.D. Jang conducted the bioassay experiments. The whole research was performed based on the planning of Y.H. Kim. All authors approved the final version of the manuscript.

Conflicts of Interest: The authors declare no competing financial interest.

\section{References}

1. Yan, X.T.; Lee, S.H.; Li, W.; Sun, Y.N.; Yang, S.Y.; Jang, H.D.; Kim, Y.H. Evaluation of the antioxidant and anti-osteoporosis activities of chemical constituents of the fruits of Prunus mume. Food Chem. 2014, 156, 408-415. [CrossRef] [PubMed]

2. Lee, S.H.; Ding, Y.; Yan, X.T.; Kim, Y.H.; Jang, H.D. Scopoletin and scopolin isolated from Artemisia iwayomogi suppress differentiation of osteoclastic macrophage RAW 264.7 cells by scavenging reactive oxygen species. J. Nat. Prod. 2013, 76, 615-620. [CrossRef] [PubMed]

3. Kim, M.H.; Ryu, S.Y.; Bae, M.A.; Choi, J.S.; Min, Y.K.; Kim, S.H. Baicalein inhibits osteoclast differentiation and induces mature osteoclast apoptosis. Food Chem. Toxicol. 2008, 46, 3375-3382. [CrossRef] [PubMed]

4. He, X.; Andersson, G.; Lindegren, U.; Li, Y. Resveratrol prevents RANKL-induced osteoclast differentiation of murine osteoclast progenitor RAW 264.7 cells through inhibition of ROS production. Biochem. Biophys. Res. Commun. 2010, 401, 356-362. [CrossRef] [PubMed]

5. Boyle, W.J.; Simonet, W.S.; Lacey, D.L. Osteoclast differentiation and activation. Nature 2003, 423, 337-342. [CrossRef] [PubMed]

6. $\quad$ Burgess, T.L.; Qian, Y.; Kaufman, S.; Ring, B.D.; Van, G.; Capparelli, C.; Kelley, M.; Hsu, H.; Boyle, W.J.; Dunstan, C.R.; et al. The ligand for osteoprotegerin (OPGL) directly activates mature osteoclasts. J. Cell Biol. 1999, 145, 527-538. [CrossRef] [PubMed]

7. Bilezikian, J.P.; Raisz, L.G.; Rodan, G.A. Principles of Bone Biology; Academic Press: San Diego, CA, USA, 2002.

8. Mizuno, T.; Wasa, T.; Ito, H.; Suzuki, C.; Ukai, N. Antitumor-active polysaccharides isolated from the fruiting body of Hericium erinaceum, an edible and medicinal mushroom called yamabushitake or houtou. Biosci. Biotechnol. Biochem. 1992, 56, 347-348. [CrossRef] [PubMed]

9. Yaoita, Y.; Danbara, K.; Kikuchi, M. Two new aromatic compounds from Hericium erinaceum (BULL.: FR.) PERS(1). Chem. Pharm. Bull. 2005, 53, 1202-1203. [CrossRef] [PubMed]

10. Kim, K.H.; Noh, H.J.; Choi, S.U.; Lee, K.R. Isohericenone, a new cytotoxic isoindolinone alkaloid from Hericium erinaceum. J. Antibiot. 2012, 65, 575-577. [CrossRef] [PubMed]

11. Ma, B.J.; Shen, J.W.; Yu, H.Y.; Yu, H.Y.; Ruan, Y.; Wu, T.T.; Zhao, X. Hericenones and erinacines: Stimulators of nerve growth factor (NGF) biosynthesis in Hericium erinaceus. Mycology 2010, 1, 92-98. [CrossRef] 
12. Ueda, K.; Tsujimori, M.; Kodani, S.; Chiba, A.; Kubo, M.; Masuno, K.; Sekiya, A.; Nagai, K.; Kawagishi, H. An endoplasmic reticulum (ER) stress-suppressive compound and its analogues from the mushroom Hericium erinaceum. Bioorg. Med. Chem. 2008, 16, 9467-9470. [CrossRef] [PubMed]

13. Miyazawa, M.; Takahashi, T.; Horibe, I.; Ishikawa, R. Two new aromatic compounds and a new D-arabinitol ester from the mushroom Hericium erinaceum. Tetrahedron 2012, 68, 2007-2010. [CrossRef]

14. Kobayashi, S.; Inoue, T.; Ando, A.; Tamanoi, H.; Ryu, I.; Masuyama, A. Total synthesis and structural revision of hericerin. J. Org. Chem. 2012, 77, 5819-5822. [CrossRef] [PubMed]

15. Ohnuma, N.; Amemiya, K.; Kakuda, R.; Yaoita, Y.; Machida, K.; Kikuchi, M. Sterol constituents from two edible mushrooms, Lentinula edodes and Tricholoma matsutake. Chem. Pharm. Bull. 2000, 48, 749-751. [CrossRef] [PubMed]

16. Luo, X.; Li, F.; Shinde, P.B.; Hong, J.; Lee, C.O.; Im, K.S.; Jung, J.H. 26,27-Cyclosterols and other polyoxygenated sterols from a marine sponge Topsentia sp. J. Nat. Prod. 2006, 69, 1760-1768. [CrossRef] [PubMed]

17. Yaoita, Y.; Yoshihara, Y.; Kakuda, R.; Machida, K.; Kikuchi, M. New sterols from two edible mushrooms, Pleurotus eryngii and Panellus serotinus. Chem. Pharm. Bull. 2002, 50, 551-553. [CrossRef] [PubMed]

18. Ishizuka, T.; Yaoita, Y.; Kikuchi, M. Sterol constituents from the fruit bodies of Grifola frondosa (FR.) S. F. Gray. Chem. Pharm. Bull. 1997, 45, 1756-1760. [CrossRef]

19. Yue, J.M.; Chen, S.N.; Lin, Z.W.; Sun, H.D. Sterols from the fungus Lactarium volemus. Phytochemistry 2001, 56, 801-806. [CrossRef]

20. Madaio, A.; Piccialli, V.; Sica, D.; Corriero, G. New polyhydrozysterols from the dictyoceratid sponges Hippospongia Communis, Spongia officinalis, Ircinia Variabilis, and Spongionella gracilis. J. Nat. Prod. 1989, 52, 952-961. [CrossRef]

21. Yan, X.H.; Liu, H.L.; Huang, H.; Li, X.B.; Guo, Y.W. Steroids with aromatic A-rings from the Hainan soft coral Dendronephthya studeri Ridley. J. Nat. Prod. 2011, 74, 175-180. [CrossRef] [PubMed]

22. Gao, H.; Hong, K.; Zhang, X.; Liu, H.W.; Wang, N.L.; Zhuang, L.; Yao, X.S. New steryl esters of fatty acids from the mangrove fungus Aspergillus awamori. Helv. Chim. Acta 2007, 90, 1165-1178. [CrossRef]

23. Huang, D.; Ou, B.; Prior, R.L. The chemistry behind antioxidant capacity assays. J. Agric. Food Chem. 2005, 53, 1841-1856. [CrossRef] [PubMed]

24. Yan, X.T.; Lee, S.H.; Li, W.; Jang, H.D.; Kim, Y.H. Terpenes and sterols from the fruits of Prunus mume and their inhibitory effects on osteoclast differentiation by suppressing tartrate-resistant acid phosphatase activity. Arch. Pharm. Res. 2014, 38, 186-192. [CrossRef] [PubMed]

25. Suh, K.S.; Lee, Y.S.; Kim, Y.S.; Choi, E.M. Sciadopitysin protects osteoblast function via its antioxidant activity in MC3T3-E1 cells. Food Chem. Toxicol. 2013, 58, 220-227. [CrossRef] [PubMed]

26. Kurihara, H.; Fukami, H.; Asami, S.; Toyoda, Y.; Nakai, M.; Shibata, H.; Yao, X.S. Effects of Oolong tea on plasma antioxidative capacity in mice loaded with restraint stress assessed using the oxygen radical absorbance capacity (ORAC) assay. Biol. Pharm. Bull. 2004, 27, 1093-1098. [CrossRef] [PubMed]

27. Aruoma, O.I.; Deiana, M.; Jenner, A.; Halliwell, B.; Kaur, H.; Banni, S.; Corongiu, F.P.; Dessi, M.A.; Aeschbach, R. Effect of hydroxytyrosol found in extra virgin olive oil on oxidative DNA damage and on low-density lipoprotein oxidation. J. Agric. Food Chem. 1998, 46, 5181-5187. [CrossRef]

28. Lautraite, S.; Bigot-Lasserre, D.; Bars, R.; Carmichael, N. Optimisation of cell-based assays for medium throughput screening of oxidative stress. Toxicol. In Vitro 2003, 17, 207-220. [CrossRef]

Sample Availability: Samples of the compounds are available from the authors.

(c) 2017 by the authors; licensee MDPI, Basel, Switzerland. This article is an open access article distributed under the terms and conditions of the Creative Commons Attribution (CC-BY) license (http:/ / creativecommons.org/licenses/by/4.0/). 